\title{
Presenting psychology research on the Internet: Obstacles and opportunities
}

\author{
MICHAEL BREZSNYAK \\ University of Colorado, Boulder, Colorado
}

\begin{abstract}
The Internet presents a potentially revolutionary tool in the dissemination of scientific information, offering many advantages to authors and audiences. However, this resource has been underutilized in psychological research because of several factors: unfamiliarity with required technology, lack of peer review, absence of an efficient centralized accessibility resource, concerns about copyright issues, and financial considerations. The present article describes the advantages of on-line presentation of research, as well as discusses various concerns about on-line publishing and the developing solutions to deal with those concerns.
\end{abstract}

The Internet presents a revolutionary tool for the dissemination of scientific information. Psychologists have recognized the potential of this innovative medium for improving scholarly publication since the earliest days of the Internet (Gardner, 1990; Harnad, 1990, 1991). Some predicted the imminent decline and eventual disappearance of paper journals (Odlyzko, 1994). Although there has been remarkable growth in the availability of psychology research papers on line in the past few years, these have not replaced paper journals, and many psychologists remain wary of presenting their work on the Internet. The present article will describe the advantages of on-line presentation of research, as well as discuss various concerns about on-line publishing and the developing solutions to such concerns.

An important distinction must be made from the outset. Although much discussion of electronic journals has already occurred, there has been little focus on the many individuals and groups of researchers who have begun to take advantage of advances in technology and make their papers available on the Internet themselves. As much as possible throughout this paper, attempts will be made to address the issues relevant to this particular subset of online publishing.

\section{ADVANTAGES OF ON-LINE PUBLICATION}

\section{Scope and Speed of Access}

On-line publication allows for instant user access to research findings at any time from virtually anywhere in the world. On-line access to literature can reduce the time spent in libraries to acquire articles and obviate the need

Thanks are due Katherine Allen, Stefano Ghirlanda, Elliott Smith, and Donald Weatherley for their helpful comments on early drafts of this paper. Please direct correspondence concerning this article to M. Brezsnyak, Department of Psychology, Campus Box 345, Boulder, CO 80309-0345 (e-mail: brez@psych.colorado.edu). for interlibrary loan services. In addition to potential direct gains in time and productivity, several secondary benefits follow from improved access. First is what can be described as the "democratization" of research and education through the Internet, a step toward leveling the academic playing field. For a small college that barely has the funds to purchase the premier journals in each field, or for a new school struggling to start up in a developing nation, the impact of on-line access to the entire corpus of literature is substantial, in both financial and academic terms. In addition, the Internet may increase the ability of related disciplines to access research, facilitating the ongoing trend toward interdisciplinary collaboration and enabling the insights often gained from such work.

In addition to these more immediate improvements in speed of retrieval of any given article, the length of time that it takes for research findings to reach their target audience can also be shortened. For on-line journals, such gains may come from technological improvements in facilities for copy editing and distribution. For individuals, the time that it takes to make findings public is virtually instant once an actual paper has been completed. This improvement in speed is augmented by the parallel trend of authors making versions of papers available to colleagues upon submitting them for review at journals. Making such "prepublication" copies available over the Internet can cut months off of the time that it takes for findings to reach target audiences. The potential of this trend is demonstrated by the vastly successful "xxx" physics preprint archive (http://xxx.lanl.gov), which has become the dominant mode of scientific communication in the physics community since its inception in 1991 (Ginsparg, 1996). Each week, the "xxx" server receives over 500,000 hits and 500 new submissions.

\section{Cost}

Internet publishing is generally considered to be substantially more cost efficient than conventional paper publishing. Odlyzko's (1998) conservative analysis of the 
costs of Ginsparg's (1996) physics paper archive versus those of conventional publishing concluded that Ginsparg's costs were roughly $2 \%-4 \%$ of those of paper publishing. Estimates of cost per article in journals ranged from $\$ 300$ to $\$ 1,000$ for on-line journals versus $\$ 2,000$ $\$ 4,000$ for their conventional paper counterparts. Figures and tables, often very costly to lay out in paper journals, would likely show particular savings in electronic media, perhaps to the extent that the role of these informationrich tools might be expanded.

The cost to individuals putting their own works on the Internet is typically no more than the time that it takes to learn the relevant skills and actually produce a file and put it on a server (not a great feat, as will be described below). Even someone who has no desire to learn about or participate in the actual process can have a paper put on line by a Web design professional for less than $\$ 100$.

\section{Type of Publications}

One of the main reasons that individuals have been putting their own articles on line independently of journals is that the Internet provides a forum for articles that might not otherwise be readily accessible (e.g., unpublished theses or conference presentations). The Internet can serve as an archive for such articles, which would otherwise be banished to file drawers. Furthermore, as Internet audio and video technology improve, other forms of scholarly communication will likely become available on line, such as lectures, conference talks, and seminars.

\section{Flexibility}

Works in progress or long-term projects that change over time can be revised easily while still being accessible to potential users. Such flexibility also allows an efficient way to correct errors in the literature and to update reports to reflect new data or findings. In addition, such methods would greatly enhance the ability for multiple authors at dispersed sites to collaborate on projects.

As we will see later, this flexibility is a double-edged sword that can create difficulties in terms of copyright and the ability to codify the scholarly canon of the field.

\section{Innovative Presentation Technology}

Internet publication provides more flexibility in how research is presented, allowing authors to include such features as JAVA applets, interactive tables and figures, and multimedia demonstrations. For example, users may someday be able to experience a study's procedure by viewing a video of it or participating in it virtually. Electronic stimuli can be presented in the form seen by the subjects, and space limitations no longer restrict the inclusion of detailed appendices including actual measures used in the study. We can also imagine interactive results sections in which readers would be able to display data in a format of their choosing or even ask certain analytic questions of the data. Such features would lend a dynamic quality to on-line works that is impossible to achieve in print and that would have the potential to enhance pa- pers' explanatory ability. Such advances are arguably the most valuable contribution of on-line publication.

\section{Open Peer Commentary}

Electronic publishing also facilitates a relatively new mode of scholarly communication, which Harnad (1990) coined "scholarly skywriting," more generally known as "open peer commentary." In this paradigm, when a new article is accepted for publication, a number of scholars in the field are invited to submit critiques, comments, relevant data, and so forth, which will be published along with the target article. Peer commentary is not intended to be a substitute for peer review, only a useful supplement (Harnad, 1997a). Although open peer commentary is not exclusive to electronic media, the capabilities of the Internet are ideal for soliciting a range of commentary that can be included with any journal or independently presented articles. Harnad (1995) considers this advantage to be the one that will sway academics to move toward electronic publication, largely because of his experience as editor of the successful open peer commentary journal $\mathrm{Be}$ havioral \& Brain Sciences.

\section{Summary}

On-line presentation of research findings has many compelling aspects in its favor. In particular, the Internet can improve access to articles, is more cost efficient than paper publishing, and facilitates innovative modes of scientific communication such as multimedia presentations and open peer commentary. The net result is that authors can increase the impact of their work, while users gain more widely available, more powerful scientific information.

\section{CONCERNS ABOUT ON-LINE PRESENTATION OF PSYCHOLOGY RESEARCH}

Several concerns currently dominate discussions of on-line research presentation. Some are warranted; others are based on misunderstanding and can be better conceptualized as obstacles to the development of on-line resources. These concerns can be summarized in the five categories below.

\section{Technical Concerns}

The most fundamental issue is an understanding of the techniques used to put research on line. For individuals who intend to put their own works on line, tasks such as creating HTML and other Internet-usable files and finding a place to host the files on the Internet can seem daunting. However, the process of putting a paper on the Internet is much easier than many people think. Although a thorough "how-to" tutorial about putting papers on the Internet is beyond the scope of this paper, a brief review of some of basic tasks involved and resources available to help prospective authors will be worthwhile.

The first step is to create an HTML or other file that is compatible with standard Web browsers. Whereas in the 
past one had to learn the awkward HTML code, several options now exist that make this process much easier. The first tool is the development of WYSIWYG ("what you see is what you get") editors that look and perform like a word processor, but that write the HTML code "invisibly" in the background. Another useful option consists of HTML translators-programs that will "translate" various kinds of word processing files into HTML with the push of a button. Such editors and translators have become readily available to users in recent years, often being incorporated into Web browsers, word processors, and office suites. Nevertheless, an increasingly popular option is to use the Adobe Acrobat ".pdf" (short for "portable document format") file format, which almost perfectly preserves features such as formatting and graphics from any input file (e.g., word processor, graphics program, etc.) with the push of a button. Trends indicate that the $\mathrm{pdf}$ file format is becoming the standard for presentation in on-line journals (Hitchcock, Carr, \& Hall, 1997). A final option for the technologically timid is to hire a professional. The amount of work such a professional would need to do on most papers is minimal, so that this ought to be fairly inexpensive. A potentially useful resource for the future would be an Internet-based form in which one could paste the various sections of a paper (e.g., Method, Results, etc.) and have a program generate the HTML files automatically.

Once the file is created, the task remains to find a server that will host it and make it available on the WorldWide Web. Most academic institutions make server space available free of charge to faculty, students, and affiliates. Commercial sites are also available for a range of prices. A few commercial sites will offer free hosting in return for allowing them to advertise on the page.

Authors need worry about none of these steps when publishing through an on-line journal. The on-line journal, however, has its own set of technological obstacles. For example, to publish on line, journals need to develop efficient and user-friendly interfaces, the means to implement the various innovative technologies that they want presented in their articles, and a system for charging customers in the case of fee-based journals. Several publishing houses and independent consultants have begun to work on these issues and implement centralized article-delivery services. As time, technology, and publishers' financial motivation to provide on-line research progress, these services should become increasingly attractive and useful to users.

\section{Quality and Reliability of Information}

The most substantial concern involves the quality of information presented on the Internet, in particular that the Internet may serve as a receptacle for low-quality articles that might best be left in file drawers rather than flood an already saturated literature. Unlike research published in paper journals, not all on-line research (particularly unpublished works put on line by individuals) is subjected to peer review. Thus, unless an on-line presen- tation is published through a peer-reviewed journal, it can be difficult to know its quality. The American Psychological Association (1997) has expressed concern that such a proliferation of non -peer-reviewed works would lead to a "market for lemons" in which an inability to distinguish grades of quality results in a general lowering of quality for all works. The rapidly growing number of new journals and other sources of on-line research may also make it difficult to identify the quality of even peer-reviewed sources.

Although many psychology researchers are trained thoroughly in the critical analysis of psychology research and might be able to make accurate quality distinctions, on-line articles have a wider reach. Academics from other fields, nonresearchers in psychology, and the general public could be misled by a methodologically questionable or theoretically biased on-line paper. In addition, funding agencies, tenure review boards, and other groups may find it harder to rely on peer review and journal quality as main indicators of an individual researcher's merits. As information becomes more accessible, the necessity of being able to discern quality accurately and effectively will become increasingly crucial.

This is a complex problem, the solution to which will have to come from multiple efforts. For paper journals expanding to offer on-line versions, there is little reason to expect a drop in quality. In fact, in light of the advantages described above, one might expect the quality of these works to increase. It will be necessary, however, to establish a hierarchy of quality for Internet sources that parallels the one that is fairly apparent (if unwritten) for paper journals (Harnad, 1996). This process would likely take some time, though the existing paper hierarchy should serve as an initial benchmark.

A critical step would be to firmly establish the use of peer review on the Internet. At the most basic level, online papers should be clearly marked as to whether or not they are peer reviewed. Although many on-line journals are already peer reviewed, there is a great need for review of the various conference reprints, unpublished theses, and various other "file-drawer" papers put on the Internet by individuals. It is possible that such a function could be performed gradually by an independent "watch-dog" organization that would develop and apply some kind of ratings system to these works. Analogous to the way in which articles are currently submitted to journals, papers could be submitted to a rating organization, which would identify and weed out inferior work. Archives or search engines could have the option of including articles only of a certain caliber. Such a system would not only provide quality information about individual papers, but could potentially change the way in which we evaluate researchers' work (rather than simply counting publications).

Fortunately, Internet-based technologies are quite conducive to the kinds of communication that are needed for efficient peer review. Newsgroups, mailing lists, filetransfer protocols (ftp), and "Web boards" are well suited to the task of having multiple individuals discuss a paper. 
These innovative Internet features have the potential to make peer review faster, more efficient, and perhaps fairer and more valid (Harnad, 1996).

\section{Accessibility of Information}

Although thousands of psychology articles are available on line (with more being added daily), there has been a concern about the ability of people to access this wealth of information efficiently and thoroughly. Large publishing groups and individual journals may have search capabilities, but these are generally restricted to that journal or publisher's works. For independently presented articles, accessibility is even more difficult. Commercial search engines are an inefficient tool for doing exhaustive literature reviews, because of the large amount of unrelated and nonscientific material returned. Lists of articles are a useful step, but these tend to be unwieldy if one is trying to cover more than a narrow topic area.

One recent attempt to centralize and organize access to on-line research is OPAL, the Online Psychology Article Listing (Brezsnyak, 1998). This free, Web-based database allows authors to provide easily accessible information about and links to their psychology-related on-line articles. OPAL differs from existing resources in several ways. First, only articles whose full text is available on line are included. Second, OPAL includes only scholarly articles that contain primary data or fairly comprehensive reviews. Finally, OPAL is searchable by abstract, author, or year. Although this resource is relatively new and still in development, it aspires to make the dissemination of on-line research much more efficient and productive.

Citation linking is another potential method to improve access to on-line works (Hitchcock, Carr, Harris, Hey, \& Hall, 1997). At the most basic level, articles can be designed with hypertext links, so that clicking on a reference will take the user to the actual source. More complex systems of citation linking such as the Distributed Link Service and other open information services are being developed through the Open Journal Project (Carr, Davis, De Roure, Hall, \& Hill, 1996; Hitchcock, Kimberley, Harris, Carr, \& Hall, 1998; Hitchcock, Quek, et al., 1997). The common theme of these methods is to provide a way to access related articles by linking them together through their reference sections.

\section{Credit and Copyright Issues}

Another common concern about on-line publication involves copyright law. Whereas conventional paper journals hold the copyright on most of the articles that they publish, individuals putting their work on line must tend to their own copyright. Some authors do not put articles on line for fear of opening themselves up to plagiarism, while others are not aware of how one goes about gaining copyright independently. Others are inhibited by the myth that putting one's work on-line places it in the "public domain" and that one thus forfeits any claim to copyright (Templeton, 1998).

Although the state of copyright law on the Internet is currently undergoing legal clarification, the consensus is fairly clear that any written work is considered copyrighted at the moment that it is fixed in any tangible form, including computer-based technologies. For now, all works presented on the Internet can be considered copyrighted upon creation, (although this applies only to the literal text and not to the underlying ideas, as is the case with copyrights in other media). In order to be able to defend a copyright legally, an author should explicitly mark his/her on-line paper as copyrighted. For additional security, papers can be registered through a number of private or governmental services.

A related issue has to do with "prepublication rules" maintained by some publishers. Such policies consider on-line works already published and thus not eligible for journal publication. Although they do serve to help regulate the existing literature, such policies slow the dissemination of research. There is a double standard here, in that a conference presentation sent to a requesting party via e-mail or "snail mail" is not considered published, whereas papers made available on the Internet are. Fortunately, this trend seems to be reversing. The APA has moderated its previous prepublication policy so that they now condone prepublication copies, although the final decision is left to individual journal editors. The emerging standard is that many editors are choosing to review articles already on the Internet with the stipulation that the article is removed once it sees print unless specific permission is given to maintain the paper on line as a reprint copy. Although progress has been made, more remains to be done in this area to ensure maximal accessibility of preprints and protection of authors' rights. This task is being taken up by organizations such as the "Campaign for the Freedom of Distribution of Scientific Work" (http:// rerumnatura.zool.su.se).

In addition, there are other, more substantial concerns about the ability of authors to claim due credit for their on-line work, which Rowland (1997) identified as one of the primary functions of scholarly journals. With the increase of ongoing open commentary and discussion (especially at the preprint stage) comes an increase in the difficulty in ascertaining the origin of a particular idea. This problem would be compounded by the existence of multiple, possibly noncurrent versions of papers. Harnad (1990) suggests that the lack of credit may be worth the potential increases in intellectual productivity. It is doubtful, however, whether individual academics, or the agencies that hire them, evaluate their tenure decisions, or fund their work, would agree to giving up one of the most established means (for better or worse) of determining one's scientific productivity and impact.

Interestingly, the solution to this problem may lie in facilitating another of Rowland's (1997) functions - namely, maintenance of a canonical archive of the literature. The creation of some centralized archive or registry, whether it be in the form of an actual repository for articles (such as that under development at the CogPrints server, http:// cogprints.soton.ac.uk) or an administrative database, is certainly possible within current technological capabilities. Such an organizing body could maintain records of 
publication and help keep track of successive versions. A potentially useful option is Odlyzko's (1994) suggestion of prohibiting the withdrawal of articles from the archive once they are submitted. This would strengthen the canonical quality of the archive and possibly help overall paper quality by encouraging authors to avoid submitting incomplete or inadequate papers.

\section{Financial Considerations}

Although costs of on-line publishing are considerably less than paper publishing, the question remains of who will pick up the tab for the editors, network administrators, archivists, and so forth, for on-line journals. Harnad (1997b) claims that it is only the failure to adequately answer this question that has kept on-line archives like physics' $x x x$ from completely eliminating paper journals. Currently, there are two main models of how this financing might work: the subscription model and a "free access" model. The subscription model is functionally similar to the present system in which users (individuals and institutions) are directly charged a subscription fee or peruse fee for access to a given journal. The "free access" model, in line with the current zeitgeist of keeping Internet resources free for all, would charge nothing to users, but would gather fees either through page charges to authors or from direct subsidies from external organizations. The financing for such a system would ultimately be absorbed by educational institutions, research funding agencies, libraries, and scientific societies.

Which model will become dominant depends in large part on who is running the on-line journals. One option is that publishing houses that currently market paper journals will make the switch to on-line versions. Publishing houses, having realized that the Internet is not a passing fad and (more to the point) that money is to be made there, have begun releasing on-line versions of many of their paper journals (sometimes at greater costs to users than the paper versions; Hitchcock, Carr, \& Hall, 1997). The other possibility is that, just as many researchers are realizing that they can put their own works on line, many editors are realizing that technology has brought them to the point that they can manage their own journals. If the load for publishing an electronic journal is small enough, editors might begin to take on the responsibilities themselves and forgo the restrictions of the publishing house (Odlyzko, 1998). The former publishing house system would maintain the current paid subscription model (as they have already begun to), while the editor-run method would remain in line with the Internet-age ideal of free access for users. Odlyzko (1998) predicts that it is likely that both free and subscription methods will develop, but that subscriptions will cost less than present rates, owing to competition from "free access" journals.

\section{CONCLUSIONS}

In the face of technological innovations, people must often catch up and adapt to rapidly changing circum- stances. Although there are many advantages to presentation of psychological research findings on the Internet, and although concerns about electronic publication have begun to be addressed through concrete solutions, we are still far from routinely using Internet-based literature. A partial explanation for this circumstance has perhaps been described best by Odlyzko (1997): "Inertia should never be underestimated." However, the caution with which the field has approached on-line publication is justified in light of the various concerns that have been raised. It is essential that the course be plotted rationally and with all of the facts on hand, rather than be motivated by general public zeal for the Internet.

Many more issues are sure to be raised as on-line publication develops. How will the field adapt to increased public access to the research literature? What will be the future of university libraries? How will the field manage and eventually integrate the existence of an on-line literature alongside the current paper literature? Will there be an integrated way of searching the entire literature? Will older publications eventually be made on line? Will there simply be too much information?

It is difficult to predict the future of on-line publication, but for now it appears that its advantages justify the continued exploration and development of the Internet as a source of scientific communication. Movement toward expansion of the role of on-line publication is likely, whether in the form of open peer commentary, financial pressures on libraries from university administrators (Odlyzko, 1996), establishment of an effective peer review system, development of a universal psychology preprint archive, or further technological advances.

It is no coincidence that the words public and publication share the same root. The purpose of a publication is to make an idea widely available to all. The Internet, as a potential tool for making psychology research more accessible, to more people, more clearly, and more efficiently, is revolutionary in that regard.

\section{REFERENCES}

American Psychological Association (1997). Publications and communications board of the APA web posting policy [WWW document]. Retrieved 7/15/98 at: http://www.apa.org/journals/fullposting. html

BREZSNYAK, M. (1998). OPAL: Online psychology article listing [WWW document]. Retrieved 7/15/98 at: http://psych-www. colorado.edu:591/opal/

Carr, L., Davis, H., De Roure, D., Hall, W., \& Hill, G. (1996). Open information services. Computer Networks and ISDN Systems, 28, 1027-1036. Retrieved 7/15/98: http://www5conf.inria.fr/fich_html/ papers/P12/Overview.html

GARDNER, W. (1990). The electronic archive: Scientific publishing for the 1990s. Psychological Science, 1, 333-341.

GINSPARG, P. (1996). Winners and losers in the global research village [WWW document]. Retrieved 10/12/98 at: http://xxx.lanl.gov/blurb/ pg96unesco.html

HARNAD, S. (1990). Scholarly skywriting and the prepublication continuum of scientific inquiry. Psychological Science, 1, 342-343. Retrieved 7/15/98 at: ftp://ftp.princeton.edu/pub/harnad/Harnad/harnad 90 . skywriting

HARNAD, S. (1991). Post-Gutenberg galaxy: The fourth revolution in 
the means of production of knowledge [WWW document]. Retrieved 7/15/98 at: ftp://ftp.princeton.edu/pub/harnad/Harnad/harnad91. postgutenberg

HARNAD, S. (1995). The postgutenberg galaxy: How to get there from here. Information Society, 11, 285-292. Retrieved 7/15/98 at: http:// cogsci.soton.ac.uk/ harnad/THES/thes.html

HARNAD, S. (1996). Implementing peer review on the net: Scientific quality control in scholarly electronic journals. In R. Peek \& G. Newby (Eds.), Scholarly publishing: The electronic frontier (pp. 103-108). Cambridge, MA: MIT Press. Retrieved 7/15/98 at: ftp://ftp.princeton. edu/pub/harnad/Harnad/HTML/harnad96.peer.review.html

HARNAD, S. (1997a). Learned inquiry and the net: The role of peer review, peer commentary, and copyright [WWW document]. Retrieved 7/15/98 at: http://citd.scar.utoronto.ca/EPub/talks/Harnad_snider. html

HARNAD, S. (1997b). The paper house of cards (and why it's taking so long to collapse). Ariadne, 8. Retrieved 7/15/98 at: http://www.ariadne. ac.uk/issue8/harnad/

HitchCock, S., CARR, L., \& HALL, W. (1997). Web journals publishing: A UK perspective. Serials, 10, 285-299. Retrieved 7/15/98 at: http://journals.ecs.soton.ac.uk/uksg.htm

Hitchcock, S., Carr, L., Harris, S., Hey, J. M. N., \& Hall, W. (1997). Citation linking: Improving access to on-line journals. In R. B. Allen \& E. Rasmussen (Eds.), Proceedings of the Second ACM international conference on digital libraries (pp. 115-122). New York: Association of Computing Machinery. Retrieved 7/15/98 at: http:// journals.ecs.soton.ac.uk/acmdl97.htm

Hitchcock, S., Kimberley, R., Harris, S., Carr, L., \& Hall, W. (1998, March). Webs of research: Putting the user in control. Paper presented at IRISS'98, Internet Research and Information for Social Scientists, Bristol, U.K. Retrieved 7/15/98 at: http://sosig.ac.uk/iriss/ papers/paper42.htm

HitchCock, S., Quek, F., Carr, L., Hall, W., Witbrock, A., \& Tarr, I. (1997, April). Linking everything to everything: Journal publishing myth or reality? Paper presented at ICCC/IFIP Conference on Electronic Publishing, Canterbury, U.K. Retrieved 7/15/98 at: http:// journals.ecs.soton. ac.uk/IFIP-ICCC97.html

ODLYZKo, A. M. (1994). Tragic loss or good riddance? The impending demise of traditional scholarly journals [Condensed version; WWW document]. Retrieved 7/15/98 at: http://www.research.att.com/ amo/ doc/tragic.loss.short.pdf

ODLYZKo, A. [M.] (1996). On the road to electronic publishing [WWW document]. Retrieved 7/15/98 at: http://www.research.att.com/ amo/ doc/tragic.loss.update

ODLYZKo, A. M. (1997). The slow evolution of electronic publishing [WWW document]. Retrieved 7/15/98 at: http://www.research.att. $\mathrm{com} / \mathrm{amo} /$ doc/slow.evolution.txt

ODLYZKo, A. [M.] (1998). The economics of electronic journals [WWW document]. Retrieved 7/15/98 at: http://www.research.att. com/ amo/doc/economics.journals.pdf

Rowland, F. (1997). Print journals: Fit for the future? Ariadne, 7. Retrieved 7/15/98 at: http://www.ariadne.ac.uk/issue7/fytton/

TEMPLETON, B. (1998). 10 big myths about copyright explained [WWW document]. Retrieved 7/15/98 at: http://www.templetons.com/ $\mathrm{brad} /$ copymyths.html

(Manuscript received October 15, 1998; revision accepted for publication January 28, 1999.) 